Sobre a akrasia

e o vínculo entre

epistemologia e
ética

Gïary/b g grdocSobre a akrasia

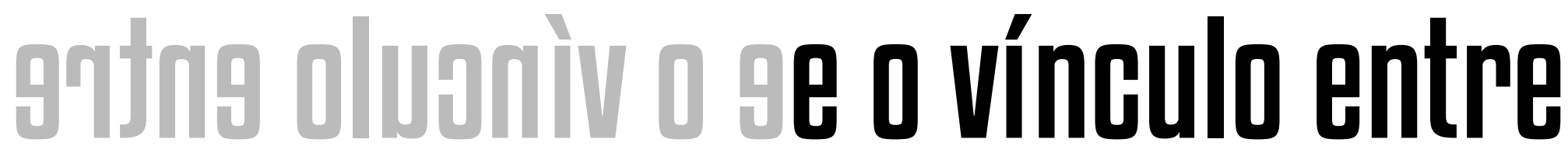

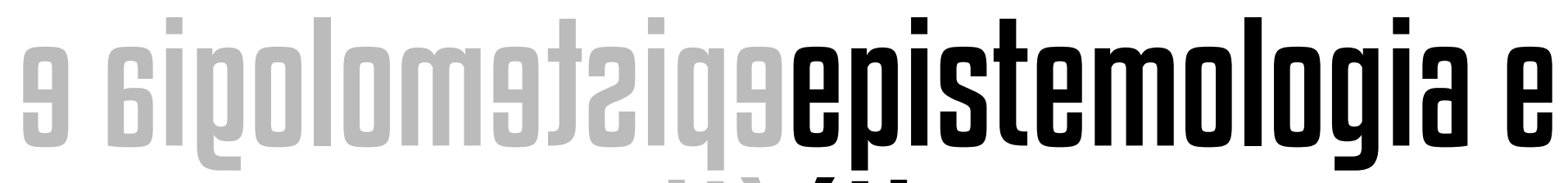

bəijàética

Sobre a akrasia

e o vínculo entre

epistemologia e

étiog 


\title{
Sobre a akrasia e o vínculo entre epistemologia e ética
}

\author{
Ian Salles Botti \\ Universidade Federal de Santa Catarina
}

RESUMO: Este artigo aborda a incontinência, ou akrasia, sob a perspectiva da epistemologia da virtude de Christopher Hookway a fim de estabelecer uma relação entre epistemologia e ética. A tese é que o fenômeno em questão possui uma contraparte epistêmica, que permite a aproximação entre as disciplinas e promove o debate acerca da validade da distinção entre áreas teóricas e práticas, descritivas e normativas. Pretende-se com isso enfatizar a centralidade do aspecto normativo da epistemologia. Os textos usados são a Ética a Nicômaco, de Aristóteles, no qual a incontinência comum é exposta no contexto de uma ética da virtude; e o artigo "Epistemic akrasia and epistemic virtue", de Hookway, no qual é defendida a possibilidade da incontinência epistêmica e de uma epistemologia da virtude. PALAVRAS-CHAVE: epistemologia; ética; incontinência; Aristóteles; Christopher Hookway. 


\section{INTRODUÇÃO}

Epistemologia e ética são áreas filosóficas a princípio bastante diferentes, dado que a primeira é comumente concebida como puramente teórica, ocupando-se com o conhecer, enquanto a segunda tem interesse predominantemente prático e dedica-se, em geral, ao agir. Seguindo Hume, muitos as consideraram incomunicáveis, sendo o domínio factual inerte em relação aos domínios passional, valorativo e moral’. Entretanto, a distinção rigorosa entre o campo de atuação desses dois ramos da filosofia talvez não seja necessária ou sequer desejável, independentemente da relação lógica entre proposições factuais e valorativas. Há a possibilidade de estabelecer relações entre as áreas, que são nosso meio de estudar duas importantes vias de interação entre homem e mundo. Essas vias, sugere Hookway

1. Hume notou que há um hiato lógico intransponível entre o que é (i.e. como as coisas são e as proposições que as descrevem) e o que deve ser (i.e. os valores e normas que adotamos). Por exemplo, o fato de que em determinado lugar e tempo certas pessoas se comportaram de certo modo não implica por si só que devemos fazer o mesmo. A implicação dessa dicotomia é a impossibilidade de inferir ou justificar valores e normas éticos, legais, estéticos e religiosos com base na experiência e em fatos e fenômenos naturais, ou seja, com base na ciência e na experiência comum (AUDI, 1999, p.302). No século XX o empirismo lógico manteve essa dicotomia, assim como a de Kant entre juízos analíticos e sintéticos, precedida pela distinção de Leibniz e Hume entre questões de fato e relações de ideias. Como resultado, Ayer, por exemplo, defendeu o emotivismo, segundo o qual proposições e conceitos avaliativos não têm a função de denotar coisas e suas propriedades, mas prescrever ou recomendar ações, comportamentos e objetivos a serem alcançados, ou seja, expressam aprovação ou desaprovação em relação a fatos possíveis (AUDI, 1999, p.260). 
(2001), estão mais próximas uma da outra do que se costuma supor ou propor na filosofia.

A epistemologia da virtude é uma corrente da epistemologia contemporânea que, tendo como influência maior a ética aristotélica, aplica conceitos de conotação moral, como virtude e responsabilidade, em teorias que visam solucionar problemas epistemológicos, tanto os tradicionais, como o ceticismo e a análise e definição do conceito de conhecimento, quanto aqueles decorrentes de sua própria abordagem (BATTALY, 2008, p.639). Entre esses últimos está a akrasia, ou incontinência, que é, de modo genérico, a ação contrária à deliberação do próprio agente, que, mesmo julgando A como um curso de ação melhor que B, faz B. Esse conceito, como veremos, tem um correspondente epistêmico. Nesse caso, portanto, o estabelecimento de um paralelo entre ética e epistemologia requer que seja possível que investigações e deliberações puramente epistêmicas sejam incontinentes.

A incontinência moral diz respeito a ações irracionais, contrárias às nossas crenças sobre o que seria melhor fazer; a incontinência epistêmica, por sua vez, tem a ver com crenças irracionais, contrárias às nossas crenças de segunda ordem que avaliam em quais estaríamos justificados a crer. Investigações e deliberações epistêmicas têm objetivo de alcançar conhecimento ou crenças verdadeiras e justificadas, independentemente de qualquer consideração ética, política, religiosa ou estética. Assim, a incontinência epistêmica depende da possibilidade de acreditarmos em algo que consideramos injustificado ou mesmo falso.

A busca pela verdade é comumente tida como o objetivo epistêmico (ou um deles) tanto da ciência quanto da filosofia, e não se reduz, mesmo se tratando de filosofia, à introspecção, contemplação ou especulação: adquirimos conhecimento agindo e explorando o mundo e nós mesmos. De fato, investigar e deliberar comportam aproximações entre moral e conhe- 
cimento. Tais atividades podem ser bem ou mal conduzidas, resultando em boas ou más ações, concernentes à ética, ou em boas e más crenças, concernentes à epistemologia.

Como Hookway discute a incontinência epistêmica no contexto de uma teoria da virtude, vamos começar com uma leitura das características principais da incontinência moral na Ética a Nicômaco (EN), de Aristóteles, para nas seções finais identificar o que a incontinência epistêmica tem de peculiar ${ }^{2}$.

\section{AÇÃO, CRÉDITO E MORALIDADE}

A que tipo de ações diz respeito a incontinência? Toda ação tem um objetivo, sendo o objetivo final da ação humana o sumo bem, ou felicidade, que é um fim absoluto e incondicional, porque é desejado em si mesmo e nunca em vista de fins ulteriores. É em vista da felicidade que todos os atos são realizados e todos os objetivos secundários (relativos ao objetivo final) são buscados (EN, I, 7, 1097b). As ciências têm fins próprios, que são absolutos, pois são buscados em si mesmos, mas não incondicionais, pois podem ser buscados em vista de outros fins (EN, I, 6, 1097a 20-30). Presume-se que o conhecimento seja um desses fins, visto que pode ser desejado tanto em si mesmo, quanto em vista de outros fins, práticos e tecnológicos, por exemplo. Não cabe aqui investigar a relação entre conhecimento e felicidade enquanto fins, basta assinalar que a verdade, ou proposições verdadeiras, são o objeto do conhecimento e, provavelmente, o principal fim das atividades epistêmicas em geral. Estas últimas são o nosso objeto de estudo, mas começaremos pela caracterização de ações morais segundo

2. Algumas teses, como a teleologia, a eudaimonia e a doutrina do meio-termo, são importantes para a apresentação da ética da virtude aristotélica, apesar de não serem defendidas por Hookway e de não serem necessárias para a compreensão do tema da akrasia. 
Aristóteles.

As ações, que podem ser certas ou erradas e objeto de elogio ou censura a quem as realiza, são as voluntárias, isto é, têm como princípio motor, no momento de sua realização, o agente, que tem conhecimento do contexto particular em que se encontra e age. Entre elas há a ação incontinente, bem como as ações impulsivas, motivadas por paixões e apetites fortes (EN, III, 1, 1111a 20). Portanto, o agente é responsável por esse tipo de ação, que tem origem nele mesmo e expressa seu caráter, isto é, ele recebe crédito ou culpa pela ação e seus resultados.

Há ainda uma categoria mais restrita entre os atos voluntários, que é a escolha:

Com efeito, tanto as crianças como os animais inferiores participam da ação voluntária, porém não da escolha; e, embora chamemos voluntários os atos praticados sob o impulso do momento, não dizemos que foram escolhidos. (EN, III, 2, 1111b 5).

Que é, então, a escolha (prohairesis)? Aristóteles a identifica com um desejo que resulta da deliberação: escolhemos aquilo a que chegamos por meio da deliberação, que versa a respeito de "coisas que estão ao nosso alcance e podem ser realizadas" (EN, III, 2, 1112a 30). Logo, deliberamos sobre ações a serem realizadas, enquanto meios, objetivando algo que não seja a própria ação, isto é, um fim ulterior. A respeito desse último não deliberamos, pois ele já é dado previamente, assim como o são as circunstâncias particulares (EN, III, 3, 1113a). Aristóteles diz o seguinte sobre o processo deliberativo que culmina na ação: "Sendo, pois, o fim aquilo que desejamos, e o meio aquilo acerca do qual deliberamos e que escolhemos, as ações relativas ao meio devem concordar com a escolha e ser voluntárias" (EN, III, 5, 1113b5). 
Ademais, segundo Aristóteles, investigações e deliberações diferem, dado que nem toda investigação inclui deliberações (EN, III, 3, 1112b25). Nas ciências dedutivas, por exemplo, há investigação, mas não deliberação, enquanto nas ciências factuais e nas artes, como a medicina e a navegação, há ambos ${ }^{3}$.

Podemos concluir que a ação incontinente não é escolhida, tampouco é resultado de deliberação, mas opõe-se a ambas (deliberação e escolha). No entanto, é voluntária, pois parte do próprio agente, que é, por isso, responsável e digno de censura por sua falha em manter-se firme em sua escolha. Segundo Aristóteles, "as paixões irracionais não são consideradas menos humanas do que a razão; por conseguinte, também as ações que procedem da cólera ou do apetite são ações do homem. Seria estranho, pois, tratá-las como involuntárias" (EN, III, 1, 1111b).

\section{CONTINÊNCIA E OUTRAS DISPOSIÇÕES DE CARÁTER}

A incontinência moral é uma forma de irracionalidade prática, na qual o agente julga que determinada ação é errada ou que determinado fim não deve ser buscado, mas, ainda assim, realiza tal ação ou busca tal fim. Com isso, a razão e o conhecimento permanecem impotentes ante as paixões, que motivam o agente a agir em desacordo com as conclusões de seu raciocínio. Contudo, para Aristóteles a akrasia não é propriamente um vício, ainda que seja uma disposição moral ruim. Por conseguinte, a continência tampouco é uma virtude (EN, VII, 1, 1145a 20). A continência e a incontinência são, então, disposições de caráter singulares ${ }^{4}$, e não uma virtude e

3. A concepção de ciência e conhecimento de Aristóteles difere muito da atual, na qual dificilmente afirmarmos que a matemática e a lógica não permitem deliberação e escolha por parte dos investigadores. Evidência disso é a existência de diversas lógicas alternativas que estendem ou substituem a clássica; o mesmo ocorre na matemática e na geometria.

4. Disposição é "uma tendência de um objeto ou sistema para agir ou reagir de formas características em determinadas situações. Fragilidade, solubilidade e radioatividade são disposições físicas típicas; generosidade e irritabilidade são disposições típicas de pessoas" (AUDI, 1999, p.238, tradução nossa). 
um vício, respectivamente.

A incontinência se relaciona com um vício em particular: a intemperança. O incontinente delibera e escolhe corretamente, mas age mal; o intemperante, por sua vez, delibera mal, e, por isso, escolhe e age mal. O primeiro raciocina em vista do fim adequado (o bem), já o segundo raciocina em vista de fins inadequados (prazeres), mas, ao agir, os dois convergem para más ações (EN, VII, 4, 1148a 15). Outra diferença entre ambos é que o resultado de suas ações difere, visto que o primeiro age com consciência de que age mal e, com isso, se arrepende, enquanto o segundo age conforme julga ser correto, de modo que não poderia ser afetado negativamente pela ação, pois a considera correta (EN, VII, 7, 1150a 20). Em suma, a falha do incontinente está na falta de comunicação entre suas deliberações e suas ações, em contrapartida, a do intemperante está em seu objetivo vicioso, que seria buscar prazeres em excesso. Portanto, a incontinência envolve a consciência da falha moral, enquanto a intemperança implica ignorar que os apetites e ações sejam viciosos (EN, VII, 8, 1150b 35). Por exemplo, o fumante incontinente decide abster-se de seu vício, consciente de que o cigarro é prejudicial a sua saúde, mas não consegue manter sua decisão e volta a fumar, sentindo-se culpado por isso; enquanto o intemperante fuma pois sente prazer com isso, ignorando os malefícios do cigarro e priorizando o prazer em detrimento da saúde, não sentindo qualquer sentimento negativo em relação a sua decisão.

Sendo assim, a continência diz respeito à capacidade de conter o apetite e as paixões, e agir conforme a razão e a virtude, levando a cabo os raciocínios práticos, apesar de possuir apetites contrários a ele. Por outro lado, a temperança consiste não em conter as paixões viciosas (se fosse o caso, não diferiria da incontinência), mas em não possuí-las. A virtude da temperança está não somente em se abster de prazeres excessivos, mas 
também em não possuir apetites excessivos ou maus (EN, VII, 2, 1146a 15), pois, segundo Aristóteles, o homem que age bem mas não encontra prazer nisso não é verdadeiramente virtuoso, e "o homem que se abstém de prazeres corporais e se deleita nessa própria abstenção é temperante, enquanto o que se aborrece com ela é intemperante" (EN, II, 3, 1104b 5). Por exemplo, o homem continente deixa de fumar e resiste ao vício, guiando-se, antes, por sua deliberação racional. Todavia, enquanto houver motivações viciosas, ele será intemperante, pois a virtude da temperança só é alcançada com o tempo e o hábito, quando ele deixar de desejar o cigarro e não sentir-se descontente por não fumar.

Também não se deve confundir continência e teimosia, pois ambas se atêm a suas deliberações e escolhas, mas diferem quanto ao conteúdo destas. Com efeito, a primeira depende da conformação do agente à razão e a escolha correta, em oposição à tentação das paixões e dos apetites; já a segunda, ocorre quando o agente se conforma a suas opiniões e escolhas, mas o faz sem razão, resistindo não às paixões, mas ao raciocínio correto (EN, VII, 8, 1151b 10), obtendo, assim, prazer em não ser persuadido, ainda que as opiniões e decisões a que se apega sejam incorretas (EN, VII, $8,1151 b$ 15). Consequentemente, a continência não implica conformar-se a qualquer regra e cumprir qualquer escolha (nisto consiste a teimosia), mas em resistir às paixões, estando, em qualquer outro caso, aberto à possibilidade de ser convencido de que suas crenças e ações estão erradas e a mudar de opinião e de conduta.

A ação incontinente é contrária aos fins e normas morais admitidas pelo agente, isto é, suas opiniões ou crenças, independentemente do valor de verdade delas. Deste modo, não importa se ele possui, de fato, conhecimento, contanto que a crença seja genuína: "a este respeito não há diferença entre conhecimento e opinião, pois alguns homens não estão menos convencidos do que pensam que do que sabem" (EN, VII, 3, 1146b 
25). Por outro lado, como vimos, é necessário à continência, para que não se confunda com a teimosia, que a deliberação e, por conseguinte a ação, estejam de acordo com a razão, e não objetivem bens meramente aparentes, como o prazer.

\section{INCONTINÊNCIA, CRENÇA E ESTRUTURA DA AÇÃO}

As teorias epistemológicas baseadas em virtudes são notadamente normativas e suas avaliações são centradas no agente e em seu caráter, e não somente em seus estados epistêmicos (i.e., estados de crença, de justificação e de conhecimento), como é o caso na epistemologia analítica tradicio-

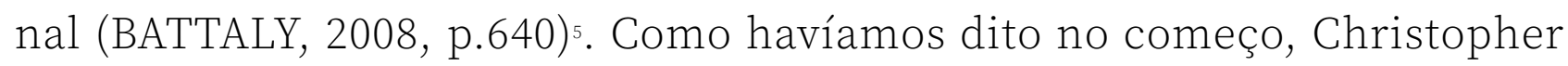
Hookway (2003) afirma que investigações e deliberações são atividades que incluem fins epistêmicos (i.e., cujo propósito é resolver problemas, responder perguntas e descobrir, como é o caso da filosofia, das ciências e seus produtos) e sugere ainda que tais atividades devem ser um dos temas centrais da epistemologia. Logo, a akrasia epistêmica depende da existência de semelhança estrutural entre o modo como agimos moralmente e o modo como conhecemos; e, mais diretamente, da possibilidade de acreditar em uma proposição e, simultaneamente, crer que ela está aquém das normas de avaliação epistêmica adotadas pelo próprio agente, ou seja, julgar que a crença nessa proposição é epistemicamente errada e, apesar disso, crer nela. Devemos, por conseguinte, responder a duas questões:

\footnotetext{
5. Algumas epistemologias da virtude são centradas em problemas e conceitos tradicionais, como por exemplo o responsabilismo de Zagebski (1998) e, sobretudo, o confiabilismo de Sosa (2017). A proposta de Hookway, porém, está entre as epistemologias da virtude autônoma moderada (Cf. BAEHR, 2008), pois se trata de uma tentativa de reorientação metodológica da disciplina influenciada pelo pragmatismo, em particular o de C. S. Peirce, que, apesar disso, não rejeita os problemas e conceitos da epistemologia tradicional; ou a tradição de Sexto Empírico e Descartes, na qual Sosa (2017), o primeiro a sugerir o emprego do conceito de virtude na teoria do conhecimento, se insere deliberadamente. Tais problemas e conceitos são somente rejeitados enquanto ponto de partida e, a fortiori, como o todo da investigação epistemológica.
} 
(i) qual a estrutura da deliberação incontinente?; e (ii) o que é necessário para que a incontinência possa ocorrer em crenças?

Comecemos então caracterizando a estrutura da ação e da incontinência moral. Na caracterização de Aristóteles, o raciocínio prático é composto de premissa maior e menor, sendo a primeira universal (uma norma, ou um objetivo) e a segunda particular (referente às circunstâncias). Por exemplo, de "a comida seca faz bem a todos os homens" e "tal comida é seca”, respectivamente, decorre, quando possível, a ação de comer. Como resultado, a incontinência ocorre no seguinte caso: "nada impede que um homem aja contrariando o seu próprio conhecimento embora possua as premissas, desde que use apenas a universal, porém não a particular; porque os atos a serem realizados são particulares” (EN, VII, 3, 1147a).

O incontinente, então, falha ao agir por não possuir ou não usar a premissa particular. A proposição de que "esta comida é seca", por exemplo, geraria a conclusão e o ato de comer, uma vez que do acordo entre premissas se segue a conclusão e, em circunstâncias apropriadas, a ação seria realizada imediatamente.

Há, com efeito, uma diferença entre possuir e usar uma crença ao raciocinar. Sendo possível que um conhecimento que o agente possui permaneça inativo em sua deliberação incontinente:

Naqueles que possuem conhecimento sem usá-lo percebemos uma diferença de estado que comporta a possibilidade de possuir conhecimento em certo sentido e ao mesmo tempo não o possuir, como sucede com os que dormem, com os loucos e os embriagados. Ora, é justamente essa a condição dos que agem sob a influência das paixões. (EN, VII, 3, 1147a 10)

Parece, então, que a akrasia ocorre devido à possibilidade de que, por causa da influência das paixões e do apetite, a crença particular não este- 
ja disponível à consciência (supondo que a deliberação seja consciente), e, consequentemente, não participe do processo deliberativo. Além disso, mesmo que o agente afirme verbalmente, a proposição em questão não implica que ele realmente acredite no que diz ou que a crença esteja ativa naquele momento. Para Aristóteles, as palavras do agente incontinente, mesmo que verdadeiras, não mostram que ele entende e acredita no que diz: "O fato de usarem uma linguagem própria do conhecimento não prova nada, (...) é de supor que o uso da linguagem por parte de homens em estado de incontinência não signifique mais que as declamações de atores em cena" (EN, VII, 3, 1147a 20).

Desse modo, na akrasia há um conflito entre premissa maior e menor, sendo a segunda incontinente: a norma expressa pela premissa maior, por exemplo "tabaco prejudica a saúde", é contradita quando o conhecimento particular de que "este cigarro contém tabaco" permanece inativo, enquanto um raciocínio alternativo, motivado pelo apetite, de que "fumar é prazeroso" e "isto é um cigarro" (com a premissa implícita de que "cigarros são fumáveis") leva à ação contrária ao conhecimento de que cigarros fazem mal à saúde. Deve-se notar que a proposição "fumar é prazeroso" em si mesma não é contrária à razão, entretanto, o apetite é, visto que conflita com o conhecimento do agente. Consequentemente, Aristóteles conclui que a crença particular que não toma parte na deliberação não pode ser uma crença genuína (ativa no raciocínio):

Ora, sendo a segunda premissa, ao mesmo tempo, uma opinião a respeito de um objeto perceptível e aquilo que determina as nossas ações, ou um homem não a possui quando se encontra no estado de paixão, ou a possui no sentido em que ter conhecimento não significa conhecer, mas apenas falar, como um bêbado que declama versos de Empédocles. (EN, VII, 3, 1147b 10) 


\section{ATIVIDADES EPISTÊMICAS, AUTOENGANO E CONFLITO DE VALORES}

Passamos agora à segunda questão, que pode ser reformulada da seguinte maneira: como é possível ter uma crença genuína, sem que ela se manifeste nas deliberações e ações do agente? Esta é a pergunta feita por Hookway (2001), que identifica um problema peculiar à incontinência do raciocínio teórico. Na incontinência moral, a crença particular permanece inativa, enquanto as paixões guiam as ações do agente. A incontinência epistêmica, por outro lado, lida primariamente com a avaliação de crenças como justificadas ou não justificadas, conhecimento ou erro etc, e não com paixões e ações, que são avaliadas pela ética como corretas ou erradas, virtuosas ou viciosas etc. Dessa forma, é necessário à akrasia epistêmica que o agente tenha consciência de que crê em desacordo com suas próprias normas de avaliação epistêmicas, assim como é necessário à akrasia moral que o agente tenha consciência de que age em desacordo com suas crenças sobre o que é moralmente correto. Para tal, na incontinência epistêmica, a crença não pode estar inativa como acontece na incontinência moral, ou seja, a crença tem que ser genuína, em oposição àquilo que se diz da boca para fora. Se, mesmo fazendo parte do processo deliberativo, a crença falhar em influenciar as atividades epistêmicas do agente, como pode-se dizer que ela esteja, de fato, ativa, ou que seja uma crença genuína? É possível que alguém creia em determinada proposição e, ao mesmo tempo, julgue epistemicamente errado assentir a ela? Como podem coexistir a crença em p e a crença de que p não é justificada?

Primeiro, devemos esclarecer o que são atividades epistêmicas. Segundo Hookway (2001, p.182), são, como quaisquer outras, atividades práticas, mas devido ao seu objetivo cognitivo, quando bem conduzidas, resultam em boas crenças (i.e., justificadas, conhecimento), caso contrá- 
rio, chega-se a crenças injustificadas e falsas. Essas atividades consistem em fazer experimentos, criar hipóteses, buscar evidências, checar argumentos e debater com outros investigadores, por exemplo. Veremos como Hookway entende a deliberação e como são possíveis duas formas de akrasia epistêmica.

O autor (Hookway, 2001, p.183) distingue entre uma forma "fraca" de incontinência epistêmica, similar à incontinência comum e caracterizada pelo autoengano; e uma forma "forte", que requer que as crenças relevantes estejam ativas e disponíveis à consciência do agente.

Hookway (2001, p.180) descreve o processo deliberativo da seguinte forma, que creio não diferir substancialmente da concepção aristotélica:

(a) O agente considera determinado fim (F) como um bem e julga que agir em vista dele seria bom;

(b) Ele decide que tal ação seria o certo, ou o melhor a ser feito;

(c) Ele resolve agir em vista de F;

(d) Ele delibera quanto ao melhor e mais eficiente meio de realizar a ação;

(e) Ele resolve agir daquela forma específica;

(f) Ele adia ou pretere a ação em vista de outros fins, que ele mesmo julga como ruins ou irrelevantes;

(g) Ele age conforme a intenção específica (e), e a decisão (c).

Uma deliberação racional requer harmonia entre avaliações, compromissos e ações, e termina, portanto, em (g). Mas deliberações incontinentes são interrompidas em estágios anteriores. Sendo assim, a incontinência consiste no conflito entre avaliações e compromissos ou entre compromissos e ações (HOOKWAY, 2001, p.181). Hookway (2001, p.180) identifica dois momentos nos quais a deliberação é interrompida prematuramente: 
(i) Entre as avaliações iniciais, (a) e (b) ou (d), e os compromissos derivados, (c) e (e). Com isso, estes últimos não são gerados, e as avaliações (que se assemelham à premissa maior em Aristóteles) não são acompanhadas de compromissos, ou intenções gerais e específicas (que se assemelham à premissa menor em Aristóteles);

(ii) No que se segue a partir da formação dos compromissos (c) e (e). Com efeito, os compromissos formados podem ser simplesmente ignorados, esquecidos, ou preteridos em prol de razões ou objetivos que o agente reconhece como ruins.

Podemos então distinguir a incontinência moral do autoengano por ser consciente, visto que o agente sabe que comporta-se de modo inapropriado e tem, geralmente, sentimentos ruins a respeito disso, tais como culpa, vergonha e arrependimento. O autoengano, por sua vez, não pode ocorrer se o agente tiver consciência de que não possui boas razões para crer ou agir do modo como faz. Conclui-se que uma contraparte epistêmica à akrasia deve diferir do autoengano, mesmo que o inclua em alguma medida ${ }^{6}$.

A incontinência epistêmica fraca não cumpre com essa demanda. Nela, o agente descumpre seus compromissos e ignora suas avaliações por desejar? que determinada crença que possui seja verdadeira e por temer que não seja o caso, i.e., que a crença particular não alcance seus padrões epistêmicos (HOOKWAY, 2001, p.183). Logo, esse tipo de incontinência impede que a crença em questão seja julgada segundo as normas epistêmicas

\footnotetext{
6. A incontinência requer que expliquemos como o agente pode avaliar positivamente um fim, mas não comprometer-se com esta avaliação, ou não agir de acordo com o comprometimento (HOOKWAY, 2001, p.181). O autoengano, por sua vez, requer que expliquemos como uma mesma pessoa pode ser o enganador e o enganado, ou seja, como diferentes conjuntos de crenças e desejos podem estar em conflito, mas não se relacionarem conscientemente e, ainda assim, pertencerem ambos a um único indivíduo, de modo que ele seja responsabilizado por sua falha.
}

7. Wishful thinking. 
aceitas pelo agente, aproximando-se, assim, do autoengano e evitando o surgimento do conflito consciente entre crenças (a saber, entre a crença normativa e a crença particular incontinente). Com isso, evita-se descobrir que a crença é falsa ao se evitar que o conflito (que caracteriza a incontinência epistêmica forte) ocorra. Por exemplo, alguém pode ter motivos para duvidar que uma crença que possui seja suficientemente suportada por evidências e razões, mas ainda assim decide mantê-la e não checar as evidências disponíveis, evitando, desse modo, descobrir que a crença a que se apega é falsa.

O que motiva o autoengano na akrasia epistêmica fraca pode ser a influência de avaliações e compromissos não epistêmicos (e.g. morais, religiosos). O agente pode ter a crença religiosamente motivada de que ninguém é verdadeiramente mau, por exemplo. Esta crença pode motivá-lo a, em suas deliberações, negligenciar evidências do contrário, agindo conforme em alguns compromissos, mas em desacordo em outros. Nesse tipo de caso, adotar valores morais ou religiosos implica incontinência epistêmica, enquanto adotar valores epistêmicos implica incontinência moral (HOOKWAY, 2001, p.184). Isso indica que valores morais e religiosos sem respaldo epistêmico podem forçar o agente a escolher entre uma ou outra akrasia. Essa discussão, porém, não será levada à frente aqui, devemos apenas mencioná-la para que, como Hookway, possamos focar em deliberações cujo objetivo seja puramente cognitivo e investigar casos de incontinência nos quais não há conflito entre padrões avaliativos epistêmicos e não epistêmicos. 


\section{INCONTINÊNCIA EPISTÊMICA, DELIBERAÇÕES E DÚVIDAS}

$\mathrm{Na}$ incontinência epistêmica forte o agente está ciente do conflito, permanece assentindo a ambas as crenças e age de acordo com a crença particular incontinente (contrário à crença normativa). Além disso, trata-se de um fenômeno que ocorre em investigações puramente cognitivas, nas quais considerações passionais, morais e religiosas não devem ter influência alguma. Consequentemente, as duas formas de incontinência de que falamos diferem no seguinte aspecto: na akrasia fraca o agente não submete sua crença particular ao escrutínio que suas avaliações e compromissos requerem (disto ele está consciente, o que qualifica seu estado como akrasia, e não simplesmente autoengano), permitindo-se manter a crença que deseja que seja verdadeira e enganando a si mesmo quanto à sua justificação ao fazê-lo; já na akrasia forte, que veremos a seguir, ele sabe que sua crença particular é improvável ou falsa, pois conflita com suas normas epistêmicas, mas a endossa mesmo assim (o conflito, portanto, é explícito e resolvido irracionalmente). A relação entre crença normativa e a crença particular geralmente é harmônica, mas na akrasia essa relação é rompida. Para que a akrasia forte seja possível, temos de compreender como a crença preterida é, ainda assim, uma crença genuína. Caso contrário, o conflito resultaria no abandono de uma das crenças em prol da outra, o que poderia resultar em uma escolha irracional, mas não em akrasia.

A formação de crença é uma ação, mas a crença não. Antes, são estados mentais do agente que, segundo Hookway (2001, p.185), se assemelham a resoluções e intenções: crer em uma proposição é adquirir um compromisso com ela, usá-la ao investigar e deliberar. Sendo assim, as crenças têm um papel causal e explicativo em relação a raciocínios, ações e até estados emocionais. Caso contrário, seria perfeitamente aceitável que al- 
guém acreditasse em $p$, e agisse de acordo com não-p; a akrasia seria um fenômeno tão comum quanto irrelevante. Contudo, para Hookway (2001, p.186), crer implica possuir disposição para agir de acordo com a proposição e não apenas assentir verbalmente a ela, o que faz com que tais crenças inertes não possam ser consideradas genuínas.

O problema, então é que o poder das crenças em causar ação entra em conflito. As crenças seriam mutuamente excludentes, porque as condicionais "se $x$ crê que $p$ e se encontrasse na situação $S$, então $x$ faria $A$ " e "se $x$ tem o compromisso normativo $N$ e se encontrasse na situação $S$, então $x$ não faria $A$ ” não podem ser, simultaneamente verdadeiras. $\mathrm{O}$ agente ou fará $A$ ou não-A, o que faz com que uma das crenças seja privada de seu poder de influenciar o comportamento.

O fato de que somos agentes reflexivos não evita esse problema, pois o agente pode, por meio da reflexão, decidir agir como julga racional sem, contudo, abandonar a crença particular incontinente ou vice-versa (a manifestação da crença no comportamento torna-se indireta, mediada pela reflexão) ${ }^{8}$. Em outras palavras, pode-se agir como se não se possuísse a crença incontinente, por se ter consciência de que essa é a forma mais racional de agir (sem corrigir a crença incontinente, mas apenas "escondendo-a"). Não penso, porém, que essa é uma solução racional ao conflito, tendo em vista a relutância do agente em abandonar a crença inadequada, preferindo, antes, assumi-la como tal e mantê-la. A akrasia permaneceria, ainda que o agente reflexivo não se comporte de forma incontinente. Ademais, a dificuldade em determinar em que consiste a crença preterida também permanece.

Hookway propõe que a solução ao problema se encontra no papel

8. A reflexão faz necessário distinguir as ações causadas pela crença em $p$ das ações causadas pela crença de que é racional ou correto crer em $p$, mesmo que não se acredite, de fato, em $p$ (HOOKWAY, 2001, p.187). 
das dúvidas e questionamentos na deliberação, e na influência das crenças não só sobre o comportamento, mas também sobre as emoções. Dúvidas e questionamentos são modos de "ativar" uma crença, de torná-la parte do processo de investigação. As questões "é o caso que p?" e "existem melhores razões para crer em $p$ que em não-p?" são distintas, podem ser feitas separadamente e admitem respostas diferentes. Qual delas é levantada pelo agente é determinante para o raciocínio: (i) a segunda questão (normativa) pode ser feita mesmo que não se tenha qualquer resposta para a primeira; e, (i) a primeira questão admite dois tipos de resposta: (a) o agente pode respondê-la "espontaneamente" com uma crença não reflexiva, ou, (b) ele pode, a partir dela, fazer a segunda pergunta, para checar sua resposta não reflexiva ou para chegar a alguma resposta. Vejamos como essas dúvidas influenciam o raciocínio incontinente.

$\mathrm{Na}$ akrasia epistêmica "forte", o agente reflexivo considera ambas as alternativas: agir de acordo com a crença particular $p$, ou com a crença normativa $N$, não sendo capaz de escolher racionalmente entre elas. Assim, ele escolhe arbitrariamente em qual questão sua investigação termina: a incontinência consiste na interrupção arbitrária da investigação em prol da alternativa preferida por motivos não epistêmicos (que não deveriam influenciar esse tipo de investigação). Trata-se de uma forma de irracionalidade prática, na qual a atividade epistêmica é sabotada por preferências emocionais, de modo que o agente mantém a crença incontinente por apegar-se a ela. No entanto, o compromisso normativo é mantido e se expressa não no comportamento, mas por meio de emoções reativas, como ansiedade, vergonha e culpa, que evidenciam a má consciência do agente em relação ao seu fracasso em levar a cabo as demandas da racionalidade, de seus compromissos normativos e da investigação puramente cognitiva que ele se propôs a realizar. ${ }^{9}$

9. As normas epistêmicas adotadas pelo agente não são necessariamente formais e explícitas, elas se manifestam também em intuições, ansiedades e reações emocionais a crenças, que são "sentidas" como 


\section{CONCLUSÃo}

Em suma, a incontinência epistêmica não pareceria um fenômeno plausível se crenças fossem estados mentais inertes, sem relação com nosso comportamento e emoções. Uma epistemologia "estática”, na qual a análise de conceitos e o enfrentamento do ceticismo radical são tudo a que se aspira, pouco poderia contribuir para a compreensão de um fenômeno como a akrasia, que interfere tanto em nossa vida moral quanto intelectual, mas que esteve, em grande parte da história da filosofia, além do alcance dos epistemólogos.

A possibilidade da ocorrência de incontinência em atividades epistêmicas nos força a reconhecer o aspecto normativo destas e explorar mais a fundo como os investigadores são responsáveis pelo seu sucesso ou fracasso. Uma alternativa é que a continência epistêmica e as demais virtudes intelectuais ${ }^{10}$ sejam disposições de caráter essenciais à regulação das investigações e à aquisição de conhecimento (HOOKWAY, 2001, p.194).

Não parece ser possível ter uma compreensão apropriada do que é conhecer e conhecimento sem levar em conta a influência (tanto positiva quanto negativa) de fatores como intuições, paixões e inclinações e preferências morais e religiosas. Tampouco se pode fazer filosofia sem ter consciência da interdisciplinaridade de seus problemas, métodos e objetivos. A epistemologia da virtude é um passo nessa direção.

inadequadas ou duvidosas, mesmo que não de forma clara. Nisso consiste o papel das emoções em evidenciar a presença da crença preterida e, com isso, a consciência do agente de que sua deliberação é incontinente.

10. Ao contrário de Aristóteles, Hookway (2006, p.196) considera a continência uma virtude e a incontinência um vício e não disposições de caráter singulares. 


\section{REFERÊNCIAS:}

ARISTÓTELES. Ética a Nicômaco. Tradução de Leonel Vallandro e Gerd Bornheim. In: ARISTÓTELES. Ética a Nicômaco. Poética. São Paulo: Abril Cultural, 1987. p.5-196.

AUDI, R. (org.). The Cambridge dictionary of philosophy. 2nd ed. Cambridge: Cambridge University Press, 1999.

BAEHR, J. Four varieties of character-based virtue epistemology. The Southern Journal of Philosophy, Hoboken, v.46, n.4, p.469-502, 2008.

BATTALY, H. Virtue epistemology. Philosophy Compass, Hoboken, v.3, n.4, p.639-663, 2008.

HOOKWAY, C. How to be a virtue epistemologist. In: DEPAUL, M.; ZAGZE BSKI, L. (org.). Intellectual virtue: perspectives from ethics and epistemology. Oxford: Oxford University Press, 2003. p.183-202.

Epistemic akrasia and epistemic virtue. In: FAIRWEATHER, A.; ZAGZEBSKI, L. (org.). Virtue epistemology: essays on epistemic virtue and responsibility. Oxford: Oxford University Press, 2001. p.178-199.

SOSA, E. Epistemology. Princeton: Princeton University Press, 2017.

ZAGZEBSKI, L. Virtues of the mind: an inquiry into the nature of virtue and the ethical foundations of knowledge. 2nd ed. Cambridge: Cambridge University Press, 1998. 